\title{
The Impact of Green Finance Development on China's Energy Structure Optimization
}

\author{
Hui Wang $\left(\mathbb{D},{ }^{1}\right.$ Lili Jiang $\left(\mathbb{D},{ }^{2}\right.$ Hongjun Duan $\mathbb{D},{ }^{3}$ Yifeng Wang $\mathbb{D},{ }^{4}$ Yichen Jiang $\mathbb{D}^{5},{ }^{5}$ \\ and Xiaoken Lin ${ }^{1}{ }^{1}$ \\ ${ }^{1}$ Pan-Asia Business School, Yunnan Normal University, Kunming, China \\ ${ }^{2}$ Business School, Suqian College, Suqian, China \\ ${ }^{3}$ School of Finance, Jiangsu Vocational College of Finance and Economics, Huaian, China \\ ${ }^{4}$ Essence Securities, Shanghai, China \\ ${ }^{5}$ Zhejiang Science and Technology Information Research Institute, Hangzhou, China \\ Correspondence should be addressed to Lili Jiang; 719821098@qq.com and Yichen Jiang; beaconspy@qq.com
}

Received 26 October 2021; Accepted 11 December 2021; Published 30 December 2021

Academic Editor: Sundarapandian Vaidyanathan

Copyright (C) 2021 Hui Wang et al. This is an open access article distributed under the Creative Commons Attribution License, which permits unrestricted use, distribution, and reproduction in any medium, provided the original work is properly cited.

\begin{abstract}
This paper studies the impact of the development of green finance on China's energy consumption structure. 17 basic indexes and the improved entropy weight method are used to construct the green finance index (GFI). Multiple regression, panel regression, and spatial regression are used to study the impact of green finance on China's traditional energy and renewable energy consumption. The results show that there is a positive spatial spillover effect in the development of green finance among provinces in China. The development of green finance contributes to the conversion of traditional to renewable energy consumption. The effect of green finance on the transformation of energy consumption structure is mainly reflected in the direct effect. The green finance in each province not only helps the local development of green energy but also plays a good role in the production and utilization of clean energy consumption in surrounding provinces. Therefore, the government should support the green finance, reduce traditional energy consumption, and increase renewable energy consumption.
\end{abstract}

\section{Introduction}

With the rapid development of countries across the world, energy consumption has become the main driving force of economic development. However, the massive consumption of energy has caused serious damage to the global ecological environment. People have criticized this kind of neglect and plunder of nature, and all countries have been called upon to develop renewable energy to maintain the balance of the ecological environment and reduce traditional energy consumption. In recent years, more and more countries have begun to realize the importance of renewable energy and environmental protection. For example, at the 19th National Congress of the Communist Party of China, facing the severe situation of tighter resource constraints, serious environmental pollution, and ecosystem degradation, there is a need to establish the concept of ecological civilization of respect for nature, to conform to nature and protect nature, and to implement a plan to ensure sustainable development. Japan put forward slogans such as "treat the environment well," "sustainable development," and "ecological way of life" to promote the concept of environmental education to the whole country, so as to deal with the increasingly complex environmental problems. In Germany, environmental protection policies have been deeply rooted in the hearts of the people. They adhere to the principle that whoever pollutes will govern, strive to achieve an environmentfriendly development model, and strive to live in harmony between man and nature. In order to better achieve the coordinated development of economy and environmental protection, people put forward the concept of green finance.

Green finance is generally regarded as an economic activity to support environmental improvement, climate change, and efficient use of resources, that is, financial 
services provided for project investment and financing, project operation, and risk management in environmental protection, energy conservation, clean energy, green transportation, green building, and other fields. Through financial services, green finance reduces the support for enterprises with high pollution and high energy consumption, encourages the development of environment-friendly enterprises, reduces the intensity of energy consumption, improves energy utilization, and optimizes the industrial structure of a nation, so as to realize the coordinated development of economic growth, green energy consumption, and environmental protection. In recent years, more and more countries have attached importance to the production and utilization of renewable energy, and the development of renewable energy has effectively improved the quality of economic development of all countries. At present, as the world's largest developing country, China's economic development and energy consumption are at the global forefront. It is of special significance to study the relationship between China's green finance development level and energy consumption structure. Therefore, it is of great theoretical and practical significance to empirically analyze the impact of China's green finance development on traditional and renewable energy consumption.

This paper will select the economic, financial, and environmental indicators of China's provinces through the improved entropy weight method to build China's Green Financial Development Index (GFI) and thereby measure the green financial development of China's provinces. This paper studies the spatial spillover effect of China's green finance development through the Moran index. More specifically, through the multiple regression model, panel regression model, and spatial Durbin model, this paper studies the impact of green finance development on traditional and renewable energy consumption. The results show that the development level of green finance in China's provinces is increasing yearly. There are obvious spatial inconsistencies in the development of green finance in China's provinces: the development of green finance in most provinces of China shows a positive spatial correlation, that is, there is a positive spatial spillover effect. Then, there is a negative correlation between the development of green finance and traditional energy consumption and a positive correlation between the development of green finance and renewable energy consumption, that is, the higher the development level of green finance, the lower the traditional energy consumption and the higher the renewable energy consumption.

\section{Literature Review}

In 1974, Germany first established an environmental bank, namely, the "ecological bank," to provide preferential lending policies for environmental protection projects. Salazar [1] first proposed the concept of environmental finance and thought that with the worsening of environment, the economy would be hit. In order to promote the coordinated development of economy and environment, it is necessary to promote the ecological environment protection and economic growth through financial means. He also thought that environmental protection and the economy can be developed in coordination with each other, which is also regarded as the embryonic form of green finance development. Cowan [2] further explains green finance on the basis of previous scholars. He thinks that green finance, as a financial innovation tool, is an interdisciplinary subject of financial theory and green economy. Green finance includes both the theory of financial and economic development and the sustainable development theory of green economy. In dealing with increasingly complex environmental problems, it can effectively solve the environmental pollution problem. White and Labatt [3] think that the development of green finance is very innovative. They fully absorb the advantages of financial development and environmental protection and combine them organically. While economic development promotes the development of environmental protection, environmental protection promotes the development of high water levels and high quality of economy. Scholtens [4] studies the internal logic of economic sustainable development and ecological environment protection, proposing that green finance can effectively solve environmental pollution problems and make the economy develop continuously and efficiently through the innovation of various financial instruments, which is the best solution to solve environmental problems. Rogger [5] pointed out that with the worsening of ecological environment, countries should formulate corresponding strategies to deal with environmental problems; in developed countries in particular, they should realize sustainable economic development and ecological environment protection through green finance and other tools. Taghizadeh-Hesary and Yoshino [6] use the investment theory model, and through empirical analysis, they find that green finance has a strong spatial spillover effect; the higher the level of green finance development, the more beneficial it will be for investors. At the same time, the development of green finance can reduce risk and improve the return rate of green energy. In contrast to Jiang et al. [7], who use the entropy weight method to measure the GFI, this paper uses the method of annual measurement to calculate it. Because the GFI measured by the entropy weight method is a relative index, this paper adopts the method of annual measurement to make the measurement result not time comparable.

At this stage, there is no research on the traditional and renewable energy consumption of green finance, but there is research on energy consumption of financial development. Some scholars believe that financial development plays a positive role in slowing down energy consumption. Shahbaz et al. [8] studied the long-term relationship between Malaysia's carbon dioxide emissions, financial development, and energy, found that financial development slowed down carbon dioxide emissions to a certain extent, and proved the relationship between the two through the Granger causality test. Abbasi and Riaz [9] used the ARDL method to study the long-term relationship between financial development and carbon emissions, and, through the vector error correction model and VECM, determined that financial variables had a greater impact on emission reduction. Khan et al. [10] explored the relationship between per capita greenhouse gas 
emissions and financial development by selecting the data of 34 middle and high-income countries in Asia and Europe. The study found that the effect of financial development on greenhouse gas emissions in each country is different, showing a negative correlation on the whole. La Rovere et al. [11] explored what the situation of greenhouse gas emissions in Brazil will be by 2050 and found that financial instruments can effectively reduce investment costs and can effectively help Brazil out of poverty. Owusu et al. [12] analyzed time series data of the United States, China, Canada, and Nigeria from 1990 to 2016, found that financial development can effectively reduce carbon dioxide emissions, and, through a machine learning method, proved that countries can reduce carbon dioxide emissions to a very low level by 2030. Atsu and Adams [13] studied the long-term relationship between energy consumption, financial development, and economic uncertainty in BRICs countries and found that policy uncertainty increases carbon dioxide emissions, while financial development will reduce carbon dioxide emissions. Chireshe [14] studied the data of South African countries from 2000 to 2016, proving that financial development can effectively improve the utilization rate of renewable energy. It is necessary to strengthen the financial development of each country to cope with the increasingly severe environmental problems.

The development of renewable energy and finance can effectively reduce carbon dioxide emissions. However, some scholars have come to different conclusions. Some believe that the development of finance cannot reduce traditional energy consumption but will instead increase the level of traditional energy consumption. Shao et al. [15] used the data of 150 economies from 1970 to 2010 to observe that the use of materials and fossil fuels will decrease economic recession and increase the use of fossil materials in economic prosperity. Therefore, there is a positive correlation between economic development and traditional energy consumption. Charfeddine and Kahia [16] selected the data of 24 countries in the Middle East and North Africa and found that the explanation of financial development on carbon dioxide emissions and energy consumption is low and financial development cannot reduce energy consumption and carbon dioxide emissions. Acheampong [17] found that energy consumption, trade openness, urbanization, and economic growth can increase carbon emissions to a certain extent.

From the existing research, we can see that the impact of financial development on energy consumption is not consistent and the impact of green finance on traditional and renewable energy consumption is scarcer. Therefore, based on the current research situation, this paper studies the impact of green finance on energy consumption by constructing the GFI and carries out the research from an empirical point of view.

\section{Development of Green Finance and Its Theoretical Analysis on Energy Consumption}

Green finance is generally regarded as guiding funds from enterprises with high pollution and high energy consumption to enterprises with low pollution and low energy consumption through financial instrument innovation. Its ultimate goal is to achieve harmonious economic and environmental development. The development of green finance can promote the optimization and upgrading of industrial structure, promote the development of technology, improve the use efficiency of energy, and reduce the consumption of fossil fuels such as coal. The impact of green financial development on energy consumption is mainly reflected in three aspects: industrial structure upgrading, technology optimization, and policy support. The relationship is shown in Figure 1:

(1) Industrial Structure Upgrading. With the development and progress of science and technology, the original development mode and energy acquisition mode no longer match the current society. The development mode of high energy consumption and high pollution cannot meet the needs of modern people for high-quality life. Therefore, green finance has come into people's vision. Green finance realizes the harmonious coexistence of economy and environment through financial instruments. Green finance helps enterprises embark on the road of industrial structure optimization and upgrading through financial support and finally realizes the adjustment of energy consumption structure.

(2) Technical Optimization. With China's continuous emphasis on green development, high emission enterprises have been continuously restricted. The development of green finance gives enterprises more funds and opportunities to seek the upgrading of energy technology. The upgrading of technology improves the use efficiency of all kinds of energy, reduces energy waste, and finally achieves the purpose of reducing energy consumption. The progress of different energy use technologies has also adjusted the energy use structure to a great extent.

(3) Policy Support. As China pays more and more attention to the development of green finance, green finance has received great policy support. This policy support sends signals to financial institutions, enterprises, and individuals, promotes people from all parties to pay attention to green development enterprises, and gives more financial support to green enterprises. With the market's attention and support for green enterprises, green enterprises can develop rapidly and accelerate enterprise technology development and industrial upgrading, so as to realize the upgrading of energy consumption structure and promote social development to be more green and efficient.

\section{Index Selection and Model Construction}

4.1. Selection of Basic Indicators. In order to accurately measure the development of green finance, 17 basic indicators are selected on the basis of the existing research [7], and the development level of green finance in China's provinces is studied from the perspectives of the economy, environment, and finance, respectively, as shown in Table 1. 


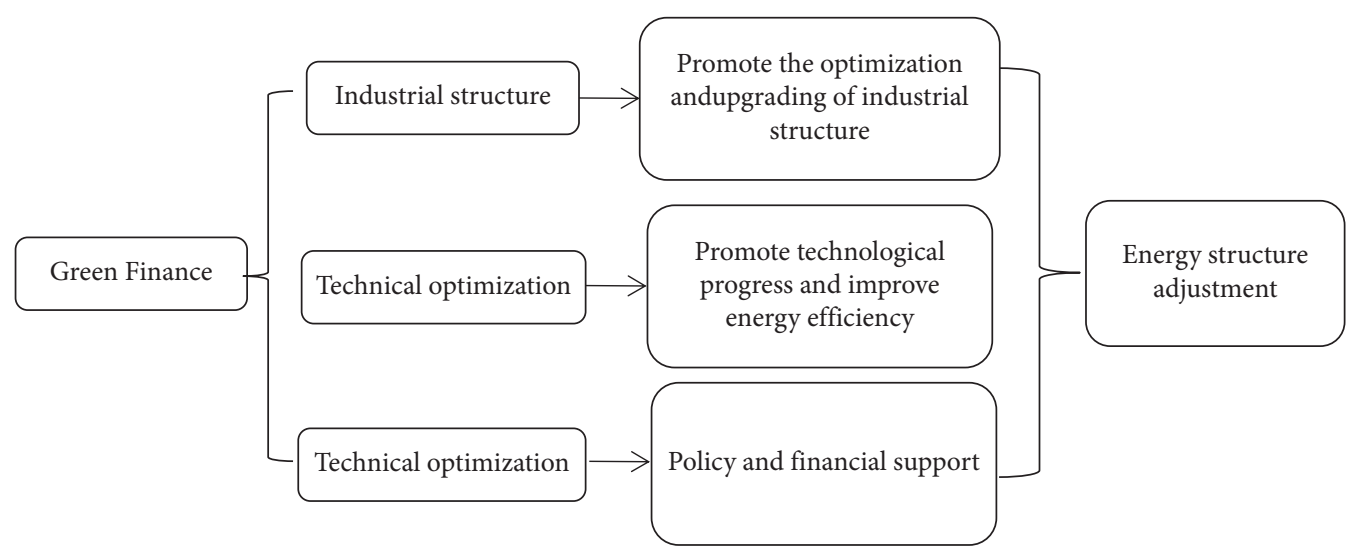

FIgURE 1: Theoretical mechanism of green finance affecting energy consumption structure.

TABLE 1: Indicator system of China's green finance development level.

\begin{tabular}{|c|c|c|c|}
\hline Dimension & Basic indicator & Attribute & Calculation method \\
\hline \multirow{3}{*}{ Economic dimension } & Unemployment rate & - & Unemployment/(unemployment + employees) \\
\hline & Per capita gross regional product & + & Gross regional product/regional population \\
\hline & Per capita disposable income & + & $\begin{array}{l}\text { Regional total disposable income/regional } \\
\text { population }\end{array}$ \\
\hline \multirow{5}{*}{$\begin{array}{l}\text { Environmental } \\
\text { dimensions }\end{array}$} & \multirow{2}{*}{$\begin{array}{c}\text { Wastewater discharge per unit of financial resources } \\
\text { Sulfur dioxide emissions per unit of financial } \\
\text { resources }\end{array}$} & - & Wastewater discharge/(deposit + loan) \\
\hline & & - & $\mathrm{SO}_{2}$ emissions/(deposit + loan) \\
\hline & Solid waste output per unit of financial resources & - & Solid waste output/(deposit + loan) \\
\hline & \multirow{2}{*}{$\begin{array}{c}\text { Energy consumption per unit of financial resources } \\
\text { Coverage rate of nature reserves under unit of } \\
\text { financial resources }\end{array}$} & - & Energy consumption/(deposit + loan $)$ \\
\hline & & + & Area of Natural Reserve/(deposit + loan) \\
\hline \multirow{9}{*}{ Financial dimension } & Forest coverage per unit financial resources & + & Forest coverage $/($ deposit + loan $)$ \\
\hline & Number of banking institutions per area & + & Number of banking institutions/regional area \\
\hline & Number of banking employees per area & + & Number of banking employees/regional area \\
\hline & Average number of banking institutions per resident & + & $\begin{array}{c}\text { Number of banking institutions/number of } \\
\text { regions }\end{array}$ \\
\hline & Average number of banking employees of residents & + & $\begin{array}{c}\text { Number of banking practitioners/regional } \\
\text { population }\end{array}$ \\
\hline & Bank deposit & + & Deposit balance of financial institutions/GDP \\
\hline & Bank loans & + & Loan balance of financial institutions/GDP \\
\hline & Insurance density & + & Premium income/number of people \\
\hline & Insurance depth & + & Premium income/GDP \\
\hline
\end{tabular}

4.2. Improved Entropy Weight Method. When measuring the development index of China's green finance, this paper selects the improved entropy weight method based on the research of Jin [18]; Lei and Qiu [19]; Li et al. [20]; and Jiang et al. [7].

Suppose that $m$ provinces are selected to measure their GFI, $n$ basic indexes are selected, and the $j-$ th index of the $i$ - th province is $x_{i j}$. This paper constructs the matrix of basic indicators of GFI, processes the positive and negative indicators, respectively, and obtains the standardized matrix by using the following formula: $r_{i j}, 0 \leq r_{i j} \leq 1$.

$$
\begin{gathered}
X=\left(x_{i j}\right)_{m \cdot n}=\left(\begin{array}{ccc}
x_{11} & \ldots & x_{1 n} \\
\vdots & \ddots & \vdots \\
x_{m 1} & \ldots & x_{m n}
\end{array}\right)_{m \cdot n}, \\
r_{i, j}= \begin{cases}\frac{x_{i j}-\min x_{i j}}{\max x_{i j}-\min x_{i j}}, & \text { if } x_{i j} \text { is a positive indicator, } \\
\frac{\max x_{i j}-x_{i j}}{\max x_{i j}-\min x_{i j}}, & \text { if } x_{i j} \text { is a negative indicator. }\end{cases}
\end{gathered}
$$


Calculate the GFI $C_{i}$ of different provinces in China:

$$
\mathrm{GFI}_{i}=\frac{s_{i}^{-}}{s_{i}^{+}+s_{i}^{-}}, \quad i=1,2, \cdots, m,
$$

where $s_{i}^{+}$and $s_{i}^{-}$are the Euclidean distance. The higher the $\mathrm{GFI}_{i}$ value, the higher the level of green finance development; the lower the $\mathrm{GFI}_{i}$ value, the lower the level of green finance development.

\subsection{Spatial Spillover Effect of Green Finance Development.} Moran's I is a key index to test the spatial spillover effect of the GFI. In this model, the original assumption is that there is no spatial autocorrelation between the green financial development of China's provinces. When the original assumption is not tenable, it means that there is a spatial autocorrelation between the green financial development of China's provinces. The value of the Moran index is generally between $[-1,1]$, greater than 0 means positive correlation and less than 0 means negative correlation. The calculation of the Moran index is shown in

$$
\begin{aligned}
I & =\frac{\sum_{i=1}^{n} \sum_{j=1}^{n} w_{i j}\left(x_{i j}-\bar{X}\right)\left(x_{j}-\bar{X}\right)}{S^{2} \sum_{i=1}^{n} \sum_{j=1}^{n} w_{i j}}, \\
S^{2} & =\frac{\sum_{i=1}^{n}\left(x_{i}-\bar{X}\right)^{2}}{n},
\end{aligned}
$$

where $w_{i j}$ is the spatial weight matrix and $S^{2}$ is the sample variance.

It is necessary to test the local Moran index and depict the local Moran scatter diagram to see whether there are heterogeneity and correlation in the development of green finance between each province and its neighboring provinces. The local Moran index is shown in

$$
I_{i}=\frac{\left(x_{i}-\bar{X}\right) \sum_{i=1}^{n} W_{i j}\left(x_{j}-\bar{X}\right)}{S^{2} \sum_{i=1}^{n} \sum_{j=1}^{n} W_{i j}} .
$$

When the Moran index is positive, it indicates that there is a positive spatial correlation between the development of green finance in China's provinces; when it is negative, it indicates that there is a negative spatial correlation.

4.4. Model Setting. Firstly, this paper uses a multivariate linear regression model to study the impact of China's green finance development on energy consumption:

$$
\begin{aligned}
& \mathrm{TEC}_{i}=\alpha+\beta_{1} \mathrm{GFI}_{i}+\beta X_{i}+\varepsilon_{i}, \\
& \mathrm{REC}_{i}=\alpha+\beta_{1} \mathrm{GFI}_{i}+\beta X_{i}+\varepsilon_{i},
\end{aligned}
$$

where $\mathrm{TEC}_{i}$ represents the level of traditional energy consumption, $\mathrm{REC}_{i}$ represents the level of renewable energy consumption, $\mathrm{GFI}_{i}$ represents the level of green finance development, $X_{i}$ represents the $i$-th control scalar, and $\varepsilon_{i}$ is the error term.

Secondly, considering that the sample data selected in this paper have obvious panel characteristics, this paper uses a panel regression model to study the impact of China's green finance development on energy consumption:

$$
\begin{aligned}
& \mathrm{TEC}_{i t}=\alpha+\beta_{1} \mathrm{GFI}_{i t}+\beta X_{i t}+\varepsilon_{i t}+u_{i}, \\
& \mathrm{REC}_{i t}=\alpha+\beta_{1} \mathrm{GFI}_{i t}+\beta X_{i t}+\varepsilon_{i t}+u_{i},
\end{aligned}
$$

where $u_{i}$ is the intercept term of individual heterogeneity and $\varepsilon_{i}$ is the error term.

Thirdly, there are some imbalances and spatial characteristics in the development of various regions in China, so this paper further uses the spatial econometric method to carry out the research:

$$
\begin{aligned}
\mathrm{TEC}_{i t}= & u_{i}+\gamma_{i}+\rho W_{i} \mathrm{TEC}_{t}+\beta_{0} W_{i} \mathrm{GFI}_{t} \\
& +\beta_{1} W_{i} X_{t}+\beta_{2} \mathrm{GFI}_{i t}+\beta X_{i t}+\varepsilon_{i t}, \\
\mathrm{REC}_{i t}= & u_{i}+\gamma_{i}+\rho W_{i} \mathrm{REC}_{t}+\beta_{0} W_{i} \mathrm{GFI}_{t} \\
& +\beta_{1} W_{i} X_{t}+\beta_{2} \mathrm{GFI}_{i t}+\beta X_{i t}+\varepsilon_{i t}, \\
\varepsilon_{i t}= & \lambda W_{i} \varepsilon_{t}+v_{i t},
\end{aligned}
$$

where $u_{i}$ is the individual effect, $\gamma_{i}$ is the time effect, $\rho$ is the spatial regression coefficient, $\lambda$ is the spatial autocorrelation coefficient, $\beta_{0}$ and $\beta_{1}$ are the regression coefficients, $W_{i}$ is the spatial weight matrix, and $\varepsilon_{i t}$ and $\nu_{i t}$ are the error terms.

There are three common spatial econometric models: the spatial error model (SEM), spatial autoregressive (SAR) model, and spatial Durbin model (SDM).

The SEM only contains the spatial autocorrelation term of error term:

$$
\begin{gathered}
\lambda \neq 0, \varepsilon_{i t}=\lambda W_{i} \varepsilon_{t}+v_{i t}, \\
\mathrm{TEC}_{i t}=u_{i}+\gamma_{i}+\beta_{0} \mathrm{GFI}_{i t}+\beta X_{i t}+\varepsilon_{i t}, \\
\mathrm{REC}_{i t}=u_{i}+\gamma_{i}+\beta_{0} \mathrm{GFI}_{i t}+\beta X_{i t}+\varepsilon_{i t} .
\end{gathered}
$$

SAR models usually contain the spatial autocorrelation terms of the explained variables:

$$
\begin{aligned}
\lambda & =0, \varepsilon_{i t}=v_{i t}, \rho \neq 0, \beta=0, \\
\mathrm{TEC}_{i t} & =u_{i}+\gamma_{i}+\rho W_{i} \mathrm{TEC}_{t}+\beta_{0} \mathrm{GFI}_{i t}+\beta X_{i t}+v_{i t}, \\
\mathrm{REC}_{i t} & =u_{i}+\gamma_{i}+\rho W_{i} \mathrm{REC}_{t}+\beta_{0} \mathrm{GFI}_{i t}+\beta X_{i t}+v_{i t} .
\end{aligned}
$$

In SDM, the spatial autocorrelation of explanatory variables is added under the limitation of SAR model:

$$
\begin{aligned}
\lambda= & 0, \varepsilon_{i t}=v_{i t}, \rho \neq 0, \beta \neq 0, \\
\mathrm{TEC}_{i t}= & u_{i}+\gamma_{i}+\rho W_{i} \mathrm{TEC}_{t}+\beta_{0} W_{i} \mathrm{GFI}_{t} \\
& +\beta_{1} W_{i} X_{t}+\beta_{2} \mathrm{GFI}_{i t}+\beta X_{i t}+v_{i t}, \\
\mathrm{REC}_{i t}= & u_{i}+\gamma_{i}+\rho W_{i} \mathrm{REC}_{t}+\beta_{0} W_{i} \mathrm{GFI}_{t} \\
& +\beta_{1} W_{i} X_{t}+\beta_{2} \mathrm{GFI}_{i t}+\beta X_{i t}+v_{i t} .
\end{aligned}
$$

In this paper, the LM test, Hausmann test, Wald test, and joint significance test are used to determine the specific model.

4.5. Variable Selection. Before the empirical analysis, the appropriate variables, i.e., those directly related to the results of the empirical analysis, must be chosen. In prior studies, 
the impact of each variable on energy consumption is not consistent and there is no complete consensus as to each variable on reducing energy consumption. Based on the existing research, this paper selects the following variables and gives a theoretical mechanism of each variable on energy consumption based on empirical analysis.

\subsubsection{Explained Variable}

(1) Traditional Energy Consumption (TEC). The logarithm of coal consumption is selected as the proxy variable of traditional energy consumption. By 2020, China's coal consumption reached $29 \%$ of the global consumption, making China, whose main energy source is coal, the largest coal consumer in the world. In China's energy consumption structure, coal consumption accounted for $57.7 \%$ in 2020 . Therefore, we take the logarithm of coal consumption as the explained variable to measure China's energy consumption level.

(2) Renewable Energy Consumption (REC). The logarithm of hydropower consumption is selected as the proxy variable of renewable energy consumption. Hydropower accounts for the largest share of China's renewable energy consumption, accounting for $44 \%$ of the country's total renewable energy consumption by May 2021. Therefore, we take hydropower consumption as the consumption of renewable energy in China to study the impact of green finance on energy structure.

\subsubsection{Explanatory Variable}

(1) Green Finance Development Level (GFI). The GFI is our core explanatory variable, but there is no unified conclusion on whether the development of green finance helps to reduce energy consumption. On the one hand, when the development level of green finance rises, the economy realizes sustainable development, promotes coordination, sustainability, and equality, and helps to reduce energy consumption. On the other hand, when the development level of green finance increases, the environmental protection requirements of the industry will increase additional costs, which will lead to more difficult operation of enterprises and may reduce the implementation of environmental protection projects. Therefore, it must be determined whether the development of green finance helps to reduce energy consumption.

\subsubsection{Control Variables}

(1) Urbanization Level (LUR). We found that the development of a region is often led by the high-pollution and highenergy-consumption enterprises. With the continuous development of the economy, the industrial structure is upgraded, the enterprises with high pollution and high energy consumption are gradually eliminated, and the population of urbanization and tertiary industry are increased. Therefore, the use of urbanization level as a control variable can effectively improve and explain the model.

(2) Industrial Structure (ISI). Energy consumption is mainly concentrated in the secondary industry, which often needs a lot of coal consumption, so the industrial structure of the secondary industry is of great significance for the study of energy consumption. When the development of green finance promotes the optimization and upgrading of industrial structure and realizes the latter, the use of industrial structure as a control variable can be effectively studied. This paper selects the logarithm of the added value of the second industry as the control variable to measure the change in industrial structure.

(3) Government Intervention Level (LGV). In order to achieve the sustainable development of the economy and environment, when the government intervention increases, it will be conducive to the implementation of green finance policy; at the same time, it will give more financial support to green enterprises, help enterprises complete the upgrading of industrial structure, and promote the better development of economy and environment. This paper selects the logarithm of government expenditure to represent the level of government intervention in economy.

(4) Economic Openness (LOPRN). When the degree of economic openness continues to improve, it is conducive to the increase in domestic exports, the continuous improvement of domestic employment, and the development of high-end technology, so as to increase the efficiency of energy use and reduce energy consumption. In this paper, the logarithm of total import and export is used to express the degree of economic openness.

(5) Generalized Technological Progress (TPI). In a broad sense, technological progress usually refers to the accumulation and improvement of various forms of knowledge covered by technology. The higher the education level of people, the higher the level of science and technology and the higher the energy utilization rate. In this paper, the logarithm of the average number of students per 100,000 people in colleges and universities is selected to represent the proxy variable of generalized technological progress.

Specific indicators are shown in Table 2.

\section{Empirical Analysis}

5.1. Data Selection and Processing. This paper selects the relevant indicators from 2004 to 2019 to build China's GFI. The data are processed as follows: (1) The data of 25 provinces and municipalities in China are selected for empirical analysis. According to the availability of data, Hong Kong, Macao, Taiwan, Tibet, Xinjiang, Ningxia, Guangxi, Neimenggu, Hainan, and other regions are excluded. (2) This paper uses the linear interpolation method to supplement some missing values in the data. (3) The data come from the Statistical Yearbooks of China's provinces 
Table 2: Definitions of main variables.

\begin{tabular}{|c|c|c|c|}
\hline Variable & Variable name & Variable meaning & Variable method \\
\hline \multirow{2}{*}{ Explained variable } & TEC & Traditional energy consumption & \multirow{8}{*}{$\begin{array}{l}\text { Logarithm of coal consumption } \\
\text { Logarithm of hydropower consumption } \\
\text { Green finance development index } \\
\text { Logarithm of urban population } \\
\text { Logarithm of added value of the secondary } \\
\text { industry } \\
\text { Logarithm of government expenditure } \\
\text { Logarithm of total import and export } \\
\text { Logarithm of the average number of student } \\
\text { in secondary and tertiary institutions per } \\
100,000 \text { people }\end{array}$} \\
\hline & & Renewable energy consumption & \\
\hline \multirow[t]{3}{*}{ Explanatory variable } & GFI & Green financial development level & \\
\hline & LUR & Urbanization level & \\
\hline & ISI & Industrial structure & \\
\hline \multirow{3}{*}{ Control variable } & LGV & Level of government intervention in economy & \\
\hline & LOPRN & Economic openness & \\
\hline & TPI & Technological progress in broad sense & \\
\hline
\end{tabular}

and their annual financial operation reports. The descriptive statistical results of the data are shown in Table 3 .

5.2. Empirical Results of the GFI. Table 4 and Figure 2 report the GFI of China's provinces. Overall, China's GFI is increasing yearly. There are some differences in the development level of green finance among different regions in China: Shanghai, Beijing, Guangdong, Jiangsu, and Zhejiang have higher initial development level of green finance and show a trend of yearly increase. In Qinghai, Guizhou, Yunnan, Gansu, and Jiangxi, the initial green finance development level is relatively low and the growth rate is relatively slow.

Further analysis shows that there is a strong spatial inconsistency in the development of green finance in China.

5.3. Spatial Spillover Effect of Green Finance Development. Table 5 shows the Moran index of green finance development in China's provinces and the corresponding statistical test results. It is not difficult to observe that the Moran index from 2004 to 2007 is not significant; however, it has been gradually significant since 2008 , and it shows the characteristics of positive spatial dependence.

Figures 3 and 4 are the local Moran I scatter diagram of 2008 and 2019. From these, we can see that the vast majority of provinces are in the first and third quadrants, which shows that the development of green finance in most provinces of China in the past two years have a positive spatial correlation. This positive correlation is that the development of green finance in each province has a positive spatial spillover effect, and the provinces with high levels of green finance development appear to be clustered. The provinces with low development levels of green finance also have agglomeration; that is, there is a trend of high agglomeration and low agglomeration.

5.4. Multiple Regression and Static Panel Regression Results of Green Finance Development on Energy Consumption. This paper uses multiple regression and panel regression to analyze the impact of green finance on energy consumption. The results of the Hausmann test are significant at the level of $1 \%$, so the fixed effect model should be chosen. The results of the correlation test and regression are shown in Tables 6 and 7.

It can be found from Table 7 that regardless of whether multiple regression or panel regression is employed, there is a negative correlation between green finance development and traditional energy consumption; that is, the higher the level of green finance development, the lower the level of energy consumption. When the development level of green finance increased by $1 \%$, under multiple regression and panel regression, traditional energy consumption decreased by $2.301 \%$ and $0.901 \%$, respectively.

It can also be found that there is a positive correlation between green finance development and renewable energy consumption. The higher the level of green finance development, the higher the level of renewable energy consumption. When the development level of green finance increased by $1 \%$, under multiple regression and panel regression, renewable energy consumption increased by $1.161 \%$ and $1.187 \%$ respectively.

From the above analysis, we can see that the development of green finance is conducive to the upgrading of energy consumption structure. With the continuous improvement of China's green finance development, the consumption of traditional energy is gradually reduced and the consumption of renewable energy is gradually increased. Therefore, the development of green finance can effectively improve the energy consumption structure. Through green finance, China improves energy consumption structure, reduces environmental pollution, and finally achieves sustainable development.

5.5. Spatial Econometric Regression Results of the Impact of Green Finance Development on Energy Consumption. In the theoretical analysis part of this paper, we introduce the commonly used spatial econometric models and use the LM test to determine whether to use the SEM model or SAR model. If we find that both are suitable, we need to consider the SDM model. At this time, we test the model through the Wald test and likelihood ratio (LR) test. After determining the model, we carry out the Hausmann test to determine whether to use the fixed-effect model or random-effect model. For spatial econometrics, we also need to conduct a joint significance test, which is used to determine whether to 
TABLE 3: Descriptive statistics of variables.

\begin{tabular}{|c|c|c|c|c|c|c|}
\hline Variable & Variable name & Sample & Average value & Standard deviation & Minimum & Maximum \\
\hline TEC & Traditional energy consumption & 400 & 4.003 & 0.3520 & 2.690 & 4.704 \\
\hline REC & Renewable energy consumption & 400 & 1.838 & 0.984 & -1.523 & 3.521 \\
\hline GFI & Green financial development level & 400 & 0.223 & 0.056 & 0.157 & 0.476 \\
\hline LUR & Urbanization level & 400 & 0.543 & 0.148 & 0.263 & 0.896 \\
\hline ISI & Industrial structure & 400 & 0.479 & 0.263 & 0.038 & 4.046 \\
\hline LGV & Level of government intervention in economy & 400 & 2.588 & 0.730 & 0.615 & 4.038 \\
\hline LOPRN & Economic openness & 400 & 3.435 & 0.374 & 2.137 & 4.237 \\
\hline TPI & Technological progress in broad sense & 400 & 3.358 & 0.174 & 2.872 & 3.838 \\
\hline
\end{tabular}

TABle 4: GFI of China's provinces from 2004 to 2019.

\begin{tabular}{|c|c|c|c|c|c|c|c|c|}
\hline Province & 2004 & $\ldots$ & 2014 & 2015 & 2016 & 2017 & 2018 & 2019 \\
\hline Beijing & 0.242 &.. & 0.347 & 0.367 & 0.395 & 0.408 & 0.405 & 0.428 \\
\hline Tianjin & 0.233 & $\ldots$ & 0.273 & 0.283 & 0.296 & 0.303 & 0.306 & 0.302 \\
\hline Hebei & 0.165 & $\ldots$ & 0.210 & 0.227 & 0.244 & 0.263 & 0.235 & 0.249 \\
\hline Shanxi & 0.165 & $\ldots$ & 0.192 & 0.204 & 0.215 & 0.218 & 0.267 & 0.283 \\
\hline Liaoning & 0.198 & $\ldots$ & 0.223 & 0.233 & 0.246 & 0.252 & 0.246 & 0.253 \\
\hline Jilin & 0.232 & $\ldots$ & 0.196 & 0.201 & 0.211 & 0.218 & 0.217 & 0.225 \\
\hline Heilongjiang & 0.203 & $\ldots$ & 0.191 & 0.197 & 0.204 & 0.216 & 0.216 & 0.229 \\
\hline Shanghai & 0.267 & $\ldots$ & 0.417 & 0.413 & 0.428 & 0.432 & 0.457 & 0.476 \\
\hline Jiangsu & 0.189 & $\ldots$ & 0.260 & 0.274 & 0.294 & 0.269 & 0.316 & 0.330 \\
\hline Zhejiang & 0.201 & $\ldots$ & 0.278 & 0.287 & 0.299 & 0.310 & 0.316 & 0.330 \\
\hline Anhui & 0.182 & $\ldots$ & 0.199 & 0.210 & 0.220 & 0.235 & 0.235 & 0.236 \\
\hline Fujian & 0.234 & $\ldots$ & 0.215 & 0.221 & 0.229 & 0.237 & 0.240 & 0.250 \\
\hline Jiangxi & 0.187 & $\ldots$ & 0.194 & 0.198 & 0.204 & 0.211 & 0.212 & 0.220 \\
\hline Shandong & 0.187 & $\ldots$ & 0.231 & 0.239 & 0.264 & 0.284 & 0.274 & 0.293 \\
\hline Henan & 0.201 & $\ldots$ & 0.218 & 0.229 & 0.243 & 0.274 & 0.269 & 0.270 \\
\hline Hubei & 0.240 & $\ldots$ & 0.200 & 0.210 & 0.215 & 0.231 & 0.237 & 0.247 \\
\hline Hunan & 0.194 & $\ldots$ & 0.190 & 0.198 & 0.207 & 0.215 & 0.226 & 0.237 \\
\hline Guangdong & 0.201 & $\ldots$ & 0.301 & 0.320 & 0.343 & 0.366 & 0.274 & 0.352 \\
\hline Chongqing & 0.259 & $\ldots$ & 0.194 & 0.204 & 0.205 & 0.215 & 0.233 & 0.239 \\
\hline Sichuan & 0.201 & $\ldots$ & 0.239 & 0.251 & 0.269 & 0.271 & 0.275 & 0.275 \\
\hline Guizhou & 0.259 & $\ldots$ & 0.175 & 0.180 & 0.186 & 0.193 & 0.195 & 0.199 \\
\hline Yunnan & 0.222 & $\ldots$ & 0.186 & 0.193 & 0.199 & 0.205 & 0.205 & 0.204 \\
\hline Shanxi & 0.207 & $\ldots$ & 0.194 & 0.202 & 0.209 & 0.216 & 0.228 & 0.229 \\
\hline Gansu & 0.166 & $\ldots$ & 0.186 & 0.195 & 0.203 & 0.202 & 0.202 & 0.204 \\
\hline Qinghai & 0.432 & $\ldots$ & 0.179 & 0.180 & 0.187 & 0.188 & 0.191 & 0.198 \\
\hline
\end{tabular}

use the individual fixed-effect model or time fixed-effect model. The specific empirical results are as follows.

From Tables 8 and 9, the LM test, LR test, and Wald test tell us that the spatial Durbin model cannot be simplified as the spatial error model and spatial lag model. Therefore, this paper will use the spatial Durbin model for research. From the results of the Hausmann test, the chi-square statistics are 21.69 and 20.06, which pass the test at the level of $10 \%$. Therefore, a fixed-effect model should be constructed. Finally, through the joint significance test which is shown in Table 10, we can see that the double fixed model should be used. The results are shown in Table 11.

The results of the spatial econometric regression further confirm that the development of green finance can improve the energy consumption structure. According to the results in Table 11, the negative relationship between green finance and traditional energy consumption can be confirmed. If the development level of green finance is increased by $1 \%$, the energy consumption will be reduced by $0.845 \%$, which is significant at the level of $1 \%$. The positive relationship between green finance and renewable energy consumption can also be confirmed. If the development level of green finance is increased by $1 \%$, the energy consumption will be increased by $1.309 \%$, which is significant at the level of $1 \%$.

5.6. Research on Direct, Indirect, and Total Effects of Green Finance Development on Energy Consumption. From Table 12, we can see that the direct and total effects of green finance development on traditional energy consumption are significant at the level of $1 \%$, while the indirect effects are not significant. This shows that the development of green finance in each province mainly contributes to the local energy conservation and emission reduction but has little impact on the reduction of traditional energy consumption in neighboring provinces. This implies that the spatial spillover effect of green finance on traditional energy consumption is not obvious.

We can also see that the direct, indirect, and total effects of green finance development on renewable energy 


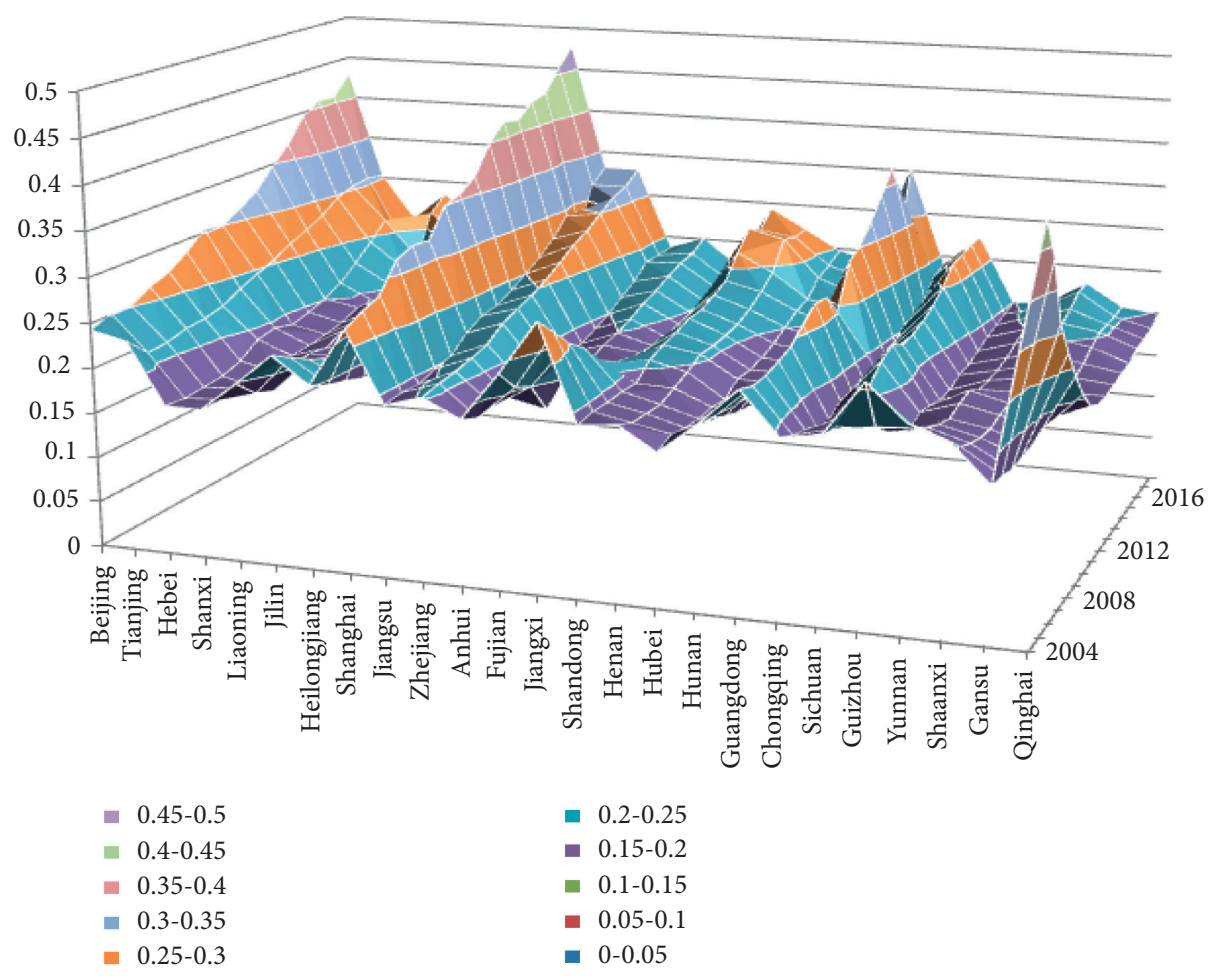

FIgURe 2: GFI of provinces and cities in China.

TABLE 5: Moran test results of green finance in China.

\begin{tabular}{lccc}
\hline Year & Moran's I & $Z$ & Prob. \\
\hline 2004 & -0.102 & -0.508 & 0.306 \\
2005 & -0.080 & -0.314 & 0.377 \\
2006 & -0.023 & 0.134 & 0.447 \\
2007 & 0.031 & 0.523 & 0.300 \\
2008 & 0.133 & 1.309 & 0.095 \\
2009 & 0.184 & 1.667 & 0.048 \\
2010 & 0.186 & 1.703 & 0.044 \\
2011 & 0.234 & 2.067 & 0.019 \\
2012 & 0.291 & 2.534 & 0.006 \\
2013 & 0.258 & 2.267 & 0.012 \\
2014 & 0.266 & 2.319 & 0.010 \\
2015 & 0.268 & 2.268 & 0.012 \\
2016 & 0.267 & 2.227 & 0.013 \\
2017 & 0.220 & 1.872 & 0.031 \\
2018 & 0.319 & 2.691 & 0.004 \\
2019 & 0.277 & 2.327 & 0.010 \\
\hline
\end{tabular}

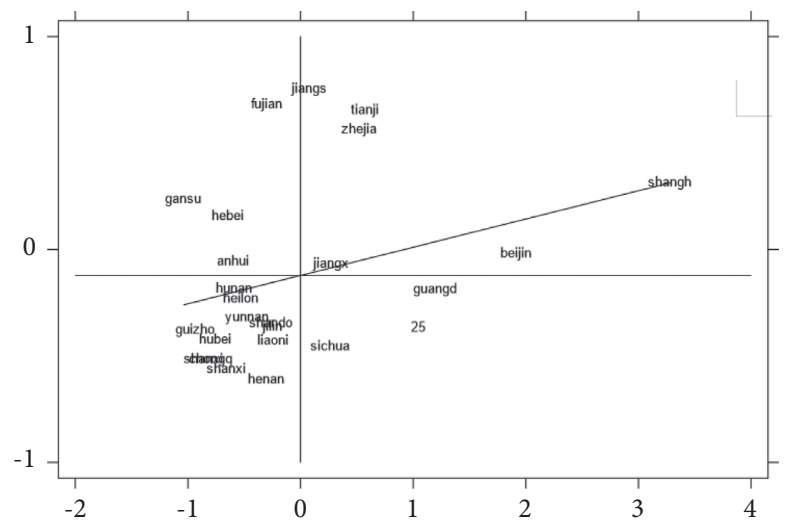

FIgURE 3: Moran I scatter plot of GFI in 2008. 


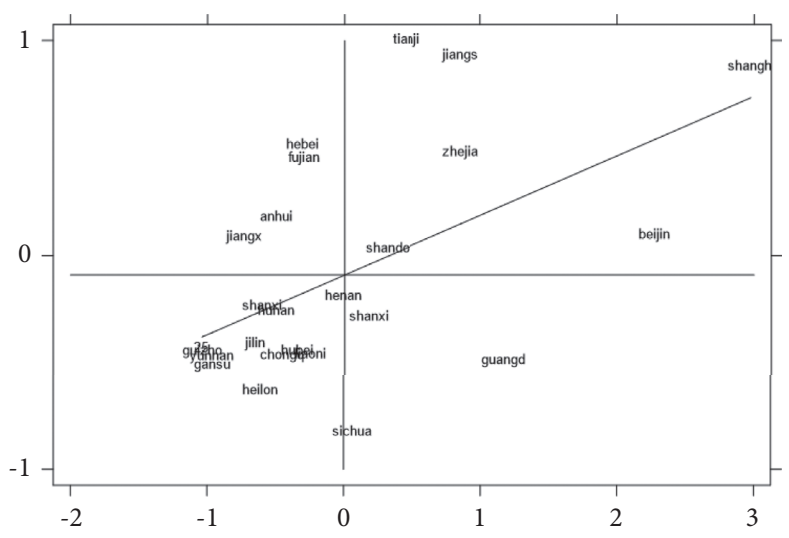

FIGURE 4: Moran I scatter plot of GFI in 2019.

TABLE 6: Results of the Hausmann test.

\begin{tabular}{lccr}
\hline Explained variable & Test summary & Chi-Sq. statistic & \\
\hline TEC & Cross section random & 123.925 & Prob. \\
REC & Cross section random & 689.730 & $\leq 0.001$ \\
\hline
\end{tabular}

TABLE 7: Results of multiple regression and static panel regression.

\begin{tabular}{|c|c|c|c|c|}
\hline \multirow{2}{*}{ Variable } & \multicolumn{2}{|c|}{ TEC } & \multicolumn{2}{|c|}{ REC } \\
\hline & Multiple regression & Panel regression & Multiple regression & Panel regression \\
\hline GFI & $-2.301^{* * *}$ & $-0.901^{* * *}$ & $1.161^{* *}$ & $1.187^{* * *}$ \\
\hline LUR & $-1.318^{* * *}$ & $0.786^{* * *}$ & $-2.457^{* * *}$ & $0.922^{* *}$ \\
\hline ISI & 0.061 & 0.011 & 0.053 & -0.039 \\
\hline LGV & $0.318^{* * *}$ & 0.030 & $-0.325^{* * *}$ & $0.141^{* *}$ \\
\hline LOPRN & $0.349^{* * *}$ & $0.051^{* *}$ & $1.220^{* * *}$ & $0.122^{* *}$ \\
\hline TPI & 0.023 & $0.304^{* * *}$ & $-1.317^{* * *}$ & 0.138 \\
\hline Constant & $3.102^{* * *}$ & $2.493^{* * *}$ & $3.961^{* * *}$ & -0.162 \\
\hline$R^{2}$ & 0.546 & 0.616 & 0.414 & 0.432 \\
\hline
\end{tabular}

${ }^{*} p<0.1,{ }^{* *} p<0.05$, and ${ }^{* * *} p<0.01$.

TABle 8: LM test.

\begin{tabular}{llcr}
\hline & & Statistic & Prob. \\
\hline \multirow{2}{*}{ TEC } & LM-lag & 6.454 & 0.011 \\
& LM-err & 423.493 & $\leq 0.001$ \\
REC & LM-lag & 445.552 & $\leq 0.001$ \\
& LM-err & 131.601 & $\leq 0.001$ \\
\hline
\end{tabular}

TABLE 9: LR test, Wald test, and Hausmann test.

\begin{tabular}{lccccc}
\hline & & LR test & Wald test & Hausmann test \\
& & SAR & SEM & 16.970 & 21.690 \\
\multirow{2}{*}{ TEC } & Statistic & 19.570 & 16.720 & 0.009 & 0.060 \\
& Prob. & 0.003 & 0.010 & 39.770 & 20.060 \\
\multirow{2}{*}{ REC } & Statistic & 37.170 & $\leq 0.19$ & $\leq 0.001$ & 0.093 \\
\hline
\end{tabular}

consumption are all significant at the level of $1 \%$. This shows that the development of green finance in each province has a certain spillover effect, which not only helps the local development of green energy but also plays a good role in the production and utilization of clean energy consumption in surrounding provinces. 
TABLE 10: Joint significance test.

\begin{tabular}{lccc}
\hline & & LR chi2 & Prob. \\
\hline \multirow{2}{*}{ TEC } & Time & 242.720 & $\leq 0.001$ \\
& Ind & 67.490 & $\leq 0.001$ \\
REC & 1008.241 & 0.000 & 1008.237 \\
& 24.633 & 0.006 & 24.632 \\
\hline
\end{tabular}

TABLE 11: Spatial Durbin model results of green finance on energy consumption.

\begin{tabular}{lcc}
\hline & TEC & REC \\
\hline GFI & $-0.845^{* * *}$ & $1.309^{* * *}$ \\
LUR & $1.332^{* * *}$ & -0.611 \\
ISI & 0.013 & -0.036 \\
LGV & $-0.079^{* * *}$ & -0.093 \\
LOPRN & -0.032 & -0.059 \\
TPI & $0.165^{* *}$ & 0.173 \\
$R^{2}$ & 0.2439 & 0.198 \\
${ }^{*} p<0.1,{ }^{* *} p<0.05$, and ${ }^{* * *} p<0.01$. & &
\end{tabular}

TABLe 12: Direct effect, indirect effect, and total effect of the spatial Durbin model.

\begin{tabular}{|c|c|c|c|c|c|c|}
\hline \multirow[b]{2}{*}{ Variables } & \multicolumn{3}{|c|}{ TEC } & \multicolumn{3}{|c|}{ REC } \\
\hline & Direct effect & Indirect effect & Total effect & Direct effect & Indirect effect & Total effect \\
\hline GFI & $-0.840^{* * *}$ & -0.038 & $-0.879^{* * *}$ & $1.399^{* * *}$ & $2.178^{* * *}$ & $3.577^{* * *}$ \\
\hline LUR & $1.310^{* * *}$ & $-0.767^{* *}$ & 0.542 & -0.618 & 0.443 & -0.175 \\
\hline ISI & 0.015 & 0.040 & $0.056^{*}$ & -0.036 & -0.104 & -0.141 \\
\hline LGV & $-0.076^{* * *}$ & $0.157^{* *}$ & 0.080 & -0.102 & -0.252 & -0.355 \\
\hline LOPEN & -0.032 & -0.012 & -0.045 & -0.066 & -0.215 & $-0.281^{* *}$ \\
\hline TPI & $0.164^{* *}$ & $-0.344^{* *}$ & -0.179 & $0.164^{* *}$ & $-0.344^{* *}$ & -0.179 \\
\hline
\end{tabular}

${ }^{*} p<0.1,{ }^{* *} p<0.05$, and ${ }^{* * *} p<0.01$.

\section{Conclusions and Suggestions}

This paper constructs China's GFI by selecting economic indicators, financial indicators, and environmental indicators and uses the improved entropy weight method to calculate the development level of green finance in China's provinces. It is found that the development level of green finance in China's provinces is on the rise, and there is a significant spatial spillover effect among provinces. Using multiple regression, panel regression, and the spatial Durbin model, it is found that the higher the development level of green finance is, the less the demand for traditional energy is and the more the consumption of renewable energy is. Moreover, the development of green finance to promote the development of clean energy has a positive external effect. Therefore, we can vigorously develop green finance to optimize the energy structure.

Based on the existing research conclusions, this paper puts forward the following policy recommendations:

(1) Giving full play to the spatial spillover effect of green finance in various regions of China, building a perfect development model of green finance. Through the above research, we can find that there is a significant spatial spillover effect between different regions in China, and the cooperation between different regions effectively reduces the traditional energy consumption. At the same time, the government should increase the support for green financial policy.
(2) Increase government support. From the above research results, it can be found that the active intervention of the government can reduce energy consumption to a certain extent. Therefore, the government should increase its support for green enterprises, guide more investors and funds into green enterprises through policy support, help green enterprises optimize industrial structure, promote enterprise technological progress, and improve energy efficiency, so as to improve energy structure and reduce energy consumption.

(3) Improve energy consumption structure through financial market. Financial market has the ability of efficient resource allocation. Through vigorously developing green finance, it can effectively restrain the consumption of traditional energy and increase the consumption of renewable energy. Developing China's green finance from three dimensions of economic development, financial development, and environmental protection can effectively promote the optimization of China's energy consumption structure.

\section{Data Availability}

The data used to support the findings of this study are available from the corresponding author upon request. 


\section{Conflicts of Interest}

The authors declare that they have no conflicts of interest.

\section{Acknowledgments}

This work was supported by 2020 Suqian Science and Technology Planning Project (Social Development), "Research on Science and Technology Finance Boosting the Development of Science and Technology SMEs in Suqian under the Background of the Epidemic" (S202005). It was also supported by Zhejiang Science and Technology Plan Project: Research and Service Support of Innovation Decision-Making in Zhejiang Province in 2021 (X2021D015). The authors thank the website of Research Square for providing a preprinted version of this article.

\section{References}

[1] J. Salazar, "Environmental finance: linking two world," 1998.

[2] E. Cowan, "Topical issues in environmental finance. economy and environment program for Southeast Asia (EEPSEA)," 1998.

[3] R. R. White and S. Labatt, Environmental Finance, John Wiley, Hoboken, NJ, USA, 2002.

[4] B. Scholtens, "Finance as a driver of corporate social responsibility," Journal of Business Ethics, vol. 68, no. 1, pp. 19-33, 2006.

[5] C. Rogger, F. Beaurain, and T. S. Schmidt, "Composting projects under the clean development mechanism: sustainable contribution to mitigate climate change," Waste Management, vol. 31, no. 1, pp. 138-146, 2011.

[6] F. Taghizadeh-Hesary and N. Yoshino, "The way to induce private participation in green finance and investment," Finance Research Letters, vol. 31, pp. 98-103, 2019.

[7] L. Jiang, H. Wang, A. Tong et al., "The measurement of green finance development index and its poverty reduction effect: dynamic panel analysis based on improved entropy method," Discrete Dynamics in Nature and Society, vol. 2020, Article ID 8851684, 13 pages, 2020.

[8] M. Shahbaz, S. A. Solarin, and H. Mahmood, "Does financial development reduce $\mathrm{CO}_{2}$ emissions in Malaysian economy? A time series analysis," Economic Modelling, vol. 35, no. 5, pp. 145-152, 2013.

[9] F. Abbasi and K. Riaz, " $\mathrm{CO}_{2}$ emissions and financial development in an emerging economy: an augmented var approach," Energy Policy, vol. 90, pp. 102-114, 2016.

[10] M. Khan, M. R. Yaseen, and Q. Ali, "Dynamic relationship between financial development, energy consumption, trade and greenhouse gas: comparison of upper middle income countries from Asia, Europe, Africa and America," Journal of Cleaner Production, vol. 161, pp. 567-580, 2017.

[11] E. L. La Rovere, C. Grottera, and W. Wills, "Overcoming the financial barrier to a low emission development strategy in Brazil," International Economics, vol. 155, pp. 61-68, 2018.

[12] E. K. Owusu, A. P. C. Chan, and E. Ameyaw, "Toward a cleaner project procurement: evaluation of construction projects' vulnerability to corruption in developing countries," Journal of Cleaner Production, vol. 216, pp. 394-407, 2019.

[13] F. Atsu and S. Adams, "Energy consumption, finance, and climate change: does policy uncertainty matter?" Economic Analysis and Policy, vol. 70, no. 4, 2021.
[14] J. Chireshe, "Finance and renewable energy development nexus: evidence from Sub-Saharan Africa," International Journal of Energy Economics and Policy, vol. 11, no. 1, pp. $318-325,2020$.

[15] Q. Shao, A. Schaffartzik, A. Mayer, and F. Krausmann, "The high "price" of dematerialization: a dynamic panel data analysis of material use and economic recession," Journal of Cleaner Production, vol. 167, pp. 120-132, 2017.

[16] L. Charfeddine and M. Kahia, "Impact of renewable energy consumption and financial development on $\mathrm{CO}_{2}$ emissions and economic growth in the mena region: a panel vector autoregressive (PVAR) analysis," Renewable Energy, vol. 139, pp. 198-213, 2019.

[17] A. O. Acheampong, "Modelling for insight: does financial development improve environmental quality?" Energy Economics, vol. 83, pp. 156-179, 2019.

[18] L. Jin, "Evaluation of green building energy-saving technology based on entropy weight method," Applied Mechanics and Materials, vol. 865, pp. 301-305, 2017.

[19] X. Lei and G. Qiu, "Empirical study about the carrying capacity evaluation of regional resources and environment based on entropy-weight topsis model," Acta Scientiae Circumstantiae, vol. 36, pp. 314-323, 2016.

[20] W. Li, P. Yi, and D. Zhang, "Sustainability evaluation of cities in northeastern China using dynamic topsis-entropy methods," Sustainability, vol. 10, no. 12, 2018. 